\title{
Prospective study of early rheumatoid arthritis. I. Prognostic value of IgA rheumatoid factor
}

\author{
INGVAR TEITSSON ${ }^{1}$ R. H. WITHRINGTON ${ }^{2}$ M. H. SEIFERT,${ }^{2}$ AND \\ HELGI VALDIMARSSON ${ }^{3}$
}

From the 'Department of Immunology, St Mary's Hospital Medical School and 'Department of Rheumatology, St Mary's Hospital, London W2, UK, and Department of Immunology, the National University Hospital, 101 Reykjavik, Iceland ${ }^{3}$

SUMmARY Thirty-three patients with early arthritis, 28 of whom developed classical/definite rheumatoid arthritis (RA), were followed up for two to four years. Rheumatoid factor (RF) levels of the IgM, IgA, and IgG isotypes were measured in serum and synovial fluid by an ELISA technique developed in our laboratory. All seven patients who presented with raised IgA RF developed erosions of their hands and wrists. This was significantly different from the remaining 26. By contrast none of the five patients who presented with isolated elevation of IgM RF developed erosive disease. The patients with raised IgA RF needed significantly more treatment with 'specific' drugs than the remaining 26 . It is suggested that the detection of IgA RF in early RA indicates poor prognosis, justifying a more aggressive treatment at an early stage.

Rheumatoid arthritis (RA) may vary in severity from one mild attack to progressive, destructive disease with early death from systemic complications. ${ }^{1}$ There is now substantial evidence that treatment with "specific" drugs like gold salts may favourably alter the course of RA. ${ }^{2}{ }^{3}$ However, toxic reactions occur in $20-40 \%$ of patients treated with gold or penicillamine, ${ }^{+}$and, since these reactions may occasionally be life-threatening, the specific drugs tend to be reserved for those with more severe disease. An early identification of patients with a poor prognosis is important because there is evidence that specific treatment is most effective early in the course of RA. ${ }^{5}$ Several workers have studied patients with early RA prospectively in an attempt to identify features of prognostic importance. Accurate prognostication in early RA is difficult, but a slow onset ${ }^{\natural}$ and strongly positive agglutination tests for rheumatoid factor $(\mathrm{RF})^{(--)}$are generally thought to imply a poor prognosis.

Agglutination tests primarily detect IgM antibodies as other antibodies are poor agglutinators. ${ }^{10}$ Rheumatoid factors of isotypes other than IgM do exist, however, and may be of fundamental importance in the pathogenesis of RA. ${ }^{11}$ The main

Accepted for publication 10 May 1984.

Correspondence to Dr M.H. Seifert. Department of Rheumatology. St Mary`s Hospital. London W2 INY. aim of the present study was to assess the clinical value of measuring individual $R F$ isotypes in early RA. The results, presented in this paper, indicate that raised serum $\operatorname{IgA} R F$ is a reliable early marker of adverse prognosis in RA. The relationship between the fluctuations in levels of RF isotypes and disease activity is presented in a separate publication. $^{12}$

\section{Materials and methods}

RHEUMATOID FACTOR ASSAYS

Enzyme-linked immunosorbent assays (ELISA) were developed for the measurement of rheumatoid factors of $\operatorname{IgM}, \operatorname{IgA}$, and $\operatorname{IgG}$ isotypes in serum and synovial fluid. ${ }^{13}$ it Flat-well microplates (M29AR, Sterilin Ltd, UK) were coated with a $10 \mu \mathrm{g} / \mathrm{ml}(\mathrm{mg} / \mathrm{l})$ solution of normal rabbit IgG and saturated with $1 \%$ bovine serum albumin (BSA). Subsequently the plates were incubated with samples diluted in PBS containing $0.5 \mathrm{M}$ sodium chloride and $0.5 \%$ Tween 20. Sample dilutions used were $1 / 10,1 / 100$, and $1 / 1000$ for IgM RF and IgA RF. Samples were diluted 1/10 only for the IgG RF assay because of low reactivity at the higher dilutions. Prior to the IgG RF assay samples were digested with pepsin (cat. no. P-7012, Sigma, London) as described by Wernick et al. ${ }^{15}$

The plates were then incubated with dilutions of 
anti-human immunoglobulins, labelled with alkaline phosphatase (AP) (type VII-S, Sigma, London) as described by Voller et al. ${ }^{16}$ Affinity-purified goat anti-human IgM (code no. 4102, TAGO Inc., USA) was used for the IgM RF assay but the $F\left(a b^{\prime}\right)_{2}$ fraction of a rabbit anti-human IgA was used for the IgA RF assay. The preparation of this latter reagent has been described in detail elsewhere. ${ }^{14}$.

In the IgG RF assay a sample incubation was followed by incubation with an unlabelled monoclonal mouse anti-human Fab-gamma (code no. 63-070, Miles Laboratories Ltd). Subsequently, the plates were incubated with the AP conjugated $\mathrm{F}\left(\mathrm{ab}^{\prime}\right)_{2}$ fraction of a goat anti-mouse IgG (code no. 4250, TAGO Inc., USA). Unlabelled mouse antibody was used because IgM RF was found to react poorly with mouse $\operatorname{IgG},{ }^{14}$ and glutaraldehydeaggregated $\mathrm{IgG}$ antibody ${ }^{16}$ may also show enhanced reactivity with IgM RF, yielding false-positive results in the presence of IgM RF.

Finally the plates were reacted with a $1 \mathrm{mg} / \mathrm{ml}$ $(\mathrm{g} / \mathrm{l})$ solution of $p$-nitrophenyl phosphate and read at $405 \mathrm{~nm}$ in a Titertek Multiskan microplate reader (Flow Laboratories).

\section{EXPRESSION AND STANDARDISATION OF RF RESULTS}

Each sample dilution was incubated in one uncoated and three adjacent IgG-coated wells. The mean net absorbance for each dilution and the combined net absorbance (CNA) for the three dilutions in the $\operatorname{IgA}$ $\mathrm{RF}$ and IgM RF assays were calculated. The mean net absorbance (IgG RF) and CNA values were read against dilution curves of internal standards and the results expressed as units (U) of RF per $\mathrm{ml}$. The internal standards were three rheumatoid sera which reacted exceptionally strongly in the respective RF assays. The IgM RF standard was calibrated against the "1st British Standard for Rheumatoid Arthritis Serum, ${ }^{17}$ and found to contain 875 international units (IU) per ml. The IgA RF and IgG RF standards were each assigned an arbitrary value of $1000 \mathrm{U} / \mathrm{ml}$.

Pepsin digestion of the IgA RF standard was found to abolish its $\operatorname{IgM}$ RF activity without affecting the IgA RF level significantly.

Sera from 102 healthy Caucasians (age range 7-80 years) were assayed for IgM RF, IgA RF, and IgG $\mathrm{RF}$ in order to establish the upper limit of normal for each RF isotype.

\section{PATIENTS STUDIED}

Thirty-three patients with early inflammatory joint disease of less than one year's duration at presentation were followed up prospectively for two to four years. These patients, who are described in more detail in a separate paper, ${ }^{12}$ presented with a peripheral synovitis suggestive of RA. The followup included three-monthly assessments of early morning stiffness (EMS), global pain using a horizontal visual analogue scale (PVAS), the Ritchie articular index (RAI), grip strength (GS), and erythrocyte sedimentation rate (ESR). The overall index of disease activity for each visit (IDA) was calculated from these five parameters. ${ }^{12}$

Serum and synovial fluid samples were collected during the follow-up, stored at $-70^{\circ} \mathrm{C}$, and assayed for the three RF isotypes at the end of the study. All samples from each patient were assayed on the same day in order to reduce errors due to day-to-day fluctuations in the assays.

Hand and wrist $x$-rays were taken at the time of entry to the study and annually thereafter. At the end of the study, two of us (R.H.W. and M.H.S.) assessed the serial films for each patient without knowledge of the identity or clinical features in order to determine the total defect score (erosions) for each film. ${ }^{18}$

\section{STATISTICAL ANAI.YSIS}

The relationship between the clinical features and the final erosion count was assessed by the Spearman's rank correlation method. Wilcoxon's twosample test, $\chi^{2}$ test with Yates's correction, and Fisher's exact probability test were used to assess the difference in outcome between those with raised and normal initial RF levels.

\section{Results}

RF ASSAYS: ASSOCIATION WITH RAHA, NORMAL RANGES

When comparing the IgM RF ELISA results with those of the RAHA sheep cell agglutination test ${ }^{19}$ we found that the CNA at dilutions $1 / 10+1 / 100+$ $1 / 1000$ correlated more closely with RAHA than the net absorbance at any single dilution. ${ }^{14}$ Consequently, samples were routinely diluted $1 / 10$ and $1 / 100$ and $1 / 1000$ in the IgM RF assay in order to obtain better quantitation and the same dilutions were used for IgA RF.

Fig. 1 shows the RF levels in the 102 normal sera. By defining the $95 \%$ level as the upper limit of normal, levels $>20$ IU IgM RF/ml, $\geqslant 10 \mathrm{U}$ IgA $\mathrm{RF} / \mathrm{ml}$ and $\geqslant 80 \mathrm{U}$ IgG $\mathrm{RF} / \mathrm{ml}$ were considered raised.

RELATIONSHIPBETWEEN THE CLINICAL/ SEROLOGICAL PRESENTATION AND HAND AND WRIST EROSIONS

Fig. 1 shows the RF levels at first visit, $4 \cdot 7 \pm 3 \cdot 0$ 


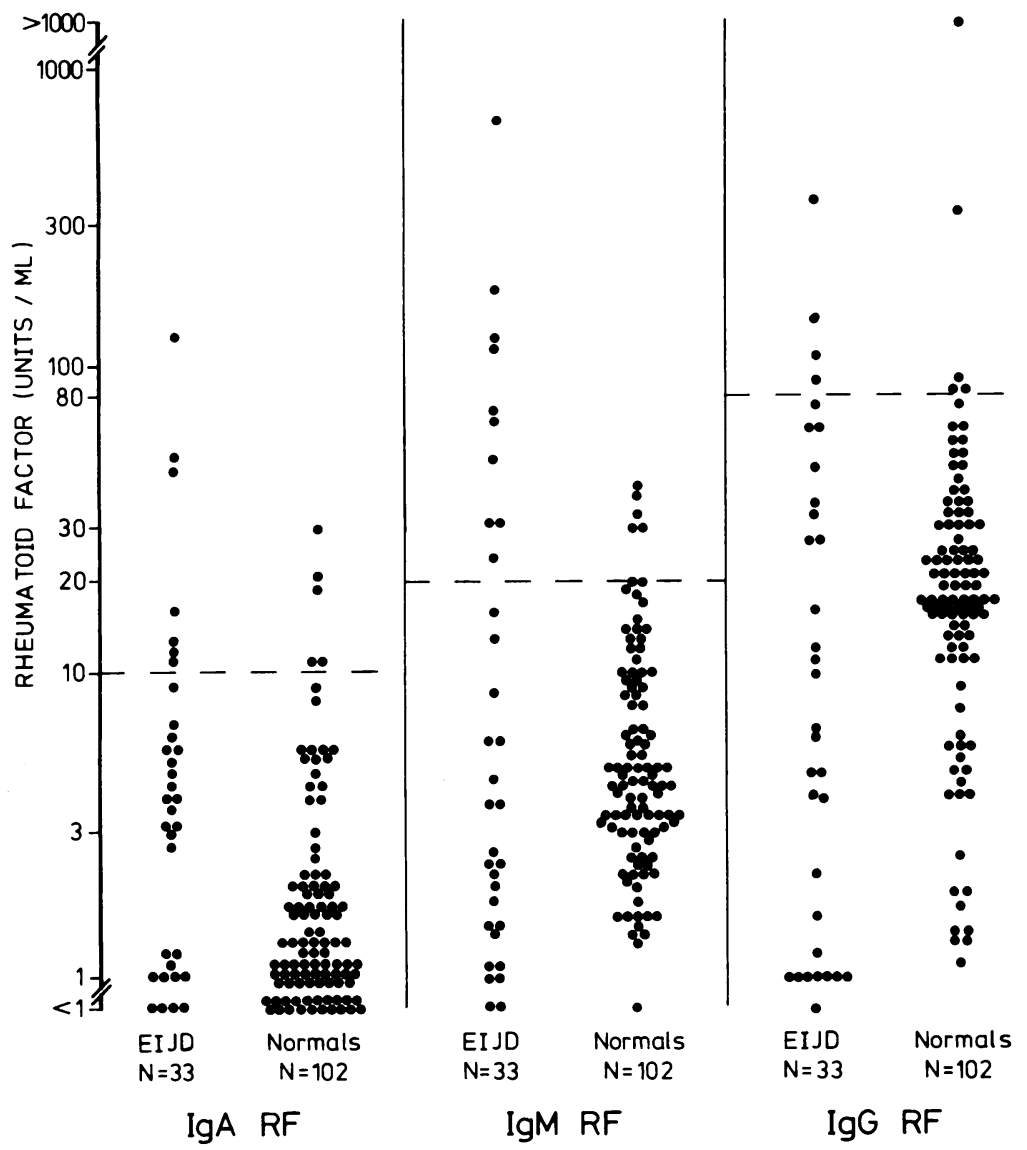

Fig. 1 The distribution of serum $\operatorname{Ig} A R F, \lg M R F$, and $\lg G R F$ levels in 102 normal persons and the RF levels at presentation in the early inflammatory joint disease (EIJD) group of 33 patients. The 95\% upper limits for the normal group (interrupted lines) are shown.

months (mean $\pm 1 \mathrm{SD}$ ) after the onset of symptoms. in the 33 patients of the prospective study group. Ten, seven, and four patients had raised levels of $\operatorname{IgM} \mathrm{RF}, \operatorname{IgA} \mathrm{RF}$, and IgG RF, respectively.

Table 1 shows the association between the final erosion count of the hands and wrists of the 33 patients and the clinical features at presentation. The initial grip strength, ESR, and the index of disease activity (IDA) correlated significantly with the erosion counts $(\mathrm{p}<0 \cdot 01)$.

Fig. 2 shows the relationship of the radiological outcome to the RF levels at presentation. Those seven who presented with raised levels of $\operatorname{IgA} R F$ all developed erosive disease, and as a group they developed a significantly greater number of erosions than the remaining 26 (median erosion counts of 11 and 0 , respectively, $p<0 \cdot() 1$. Wilcoxon's two-sample test). The five patients who never met the ARA criteria for classical/definite RA all presented with normal IgA RF. When these five patients were eliminated from the analysis, the difference in

erosion counts was still significant $(\mathrm{p}<0 \cdot 02$, Wilcoxon's two-sample test). By contrast, those 10 who presented with raised serum IgM RF did not develop more erosions than the remaining 23 (median erosion counts of 0.5 and 1 , respectively).

Table 1 The association in the group of 33 between the final erosion count of the hands and wrists and clinical features at first and last visit

\begin{tabular}{|c|c|c|}
\hline & $r^{*}$ & $\mathrm{P}<$ \\
\hline Age at onset & $0 \cdot 350$ & 0.05 \\
\hline EMS at onset & 0.384 & 0.015 \\
\hline PVAS at onset & $(0 \cdot() 21$ & NS \\
\hline RAI at onset & $0 \cdot 412$ & $0 \cdot(1) 2$ \\
\hline GS at onset & $-0 \cdot 547$ & $0 \cdot() 1$ \\
\hline ESR at onset & $0 \cdot 472$ & $0 \cdot 01$ \\
\hline IDA at onset & 0.487 & $0 \cdot(01$ \\
\hline RAI at last visit & $0 \cdot 482$ & 0.01 \\
\hline GS at last visit & -0.684 & $0 .(00) 1$ \\
\hline IDA at last visit & $0 \cdot 544$ & $0 \cdot(01$ \\
\hline
\end{tabular}

${ }^{*} r_{\text {: }}$ Spcarman's rank correlation coefficient. 
Similarly, those four who presented with raised IgG RF did not fare significantly worse than those with normal IgG RF (median erosion counts of 2 and 1 , respectively).

Five of those who presented with raised IgA RF also had raised serum IgM RF. However, Table 2

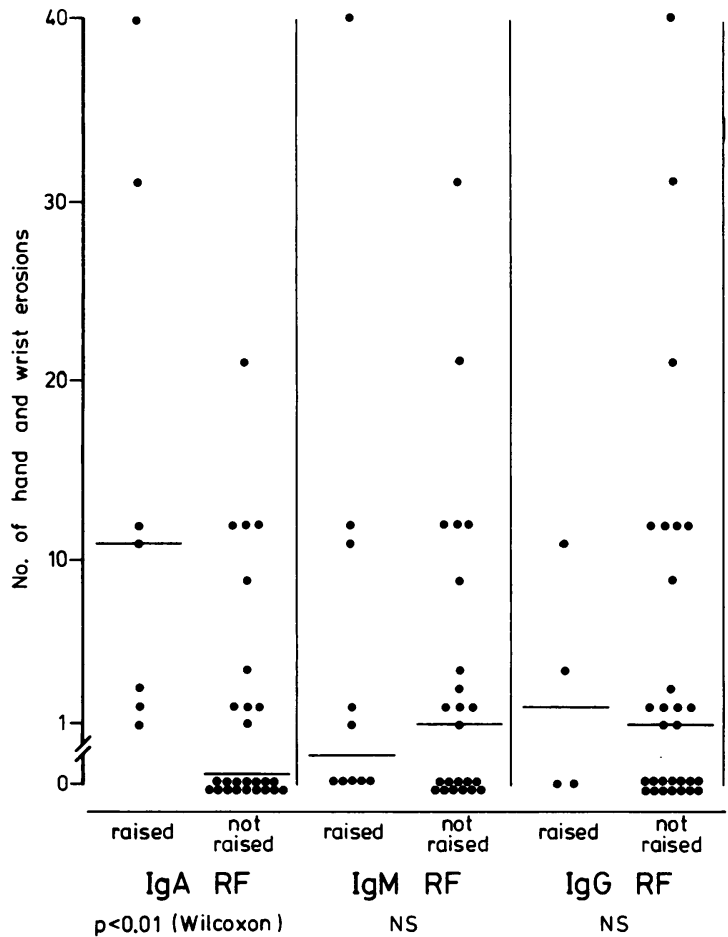

Fig. 2 The relationship between $R F$ levels at onset and the subsequent development of hand and wrist erosions in the group of 33 patients. The seven who had raised $\operatorname{Ig} A R F$ developed significantly greater number of erosions than the remaining 26 ( $p<0.01$, Wilcoxon's two-sample test). The bars indicate the median erosion counts for each group.

Table 2 The relationship of erosive hand and wrist disease to an isolated rise in $\operatorname{IgMRF}$ and raised $\operatorname{Ig} A R F$ at the first visit

\begin{tabular}{llll}
\hline & \multicolumn{2}{l}{$\begin{array}{l}\text { Hand and wrist disease } \\
\text { (no. of patients) }\end{array}$} & \\
\cline { 2 - 3 } & Erosive & Non-erosive & $p^{*}$ \\
\hline $\begin{array}{l}\text { Raised IgM RF with } \\
\text { normal IgA RF }\end{array}$ & 0 & 5 & \\
$\begin{array}{l}\text { Raised IgA RF with/ } \\
\text { without raised } \\
\text { IgM RF }\end{array}$ & 7 & 0 & \\
\hline
\end{tabular}

${ }^{*}$ p: Fisher's exact probability test. shows that the five patients who presented with a selective increase in IgM RF remained free of erosions, in striking contrast to those seven who presented with raised IgA RF with/without raised IgM RF, as the latter group developed erosive disease without exception. This difference was statistically significant $(p=0 \cdot 0013$, Fisher's exact probability test).

ASSOCIATION BETWEEN RF LEVELS AT ONSET

AND DISEASE ACTIVITY AT THE END OF THE

STUDY

Those seven patients who presented with raised $\operatorname{IgA}$ RF had significantly higher ESR and poorer grip strength than the rest of the group at the end of the study (Table 3). However, there was no such association between raised IgM RF or IgG RF at onset and disease activity at the last visit.

\section{ASSOCIATION BETWEEN RF LEVELS AT FIRST VISIT AND SUBSEQUENT TREATMENT}

Fourteen of the $28 \mathrm{RA}$ patients in the prospective group were treated with gold (sodium aurothiomalate), penicillamine, or oral prednisolone during the follow-up. Table 4 shows the relationship between raised/normal IgA RF at first visit and the subsequent requirement for gold, penicillamine, and prednisolone. By assuming that we had a choice of

Table 3 The relationship between IgA RF levels at first visit and the grip strength and ESR at the last visit

\begin{tabular}{lllcc}
\hline & $\begin{array}{l}\text { lgA } R F \\
\text { (onset) }\end{array}$ & $\begin{array}{l}\text { Number of } \\
\text { patients }\end{array}$ & Median & $p<*$ \\
\hline $\begin{array}{l}\text { Final GS } \\
(\mathrm{mmHg})\end{array}$ & $\geqslant 10 \mathrm{U} / \mathrm{ml}$ & 7 & 93 & 0.05 \\
& $<10 \mathrm{U} / \mathrm{ml}$ & 26 & 211 & \\
$\begin{array}{l}\text { Final ESR } \\
(\mathrm{mm} / \mathrm{h})\end{array}$ & $\geqslant 10 \mathrm{U} / \mathrm{ml}$ & 7 & 31 & 0.05 \\
\hline
\end{tabular}

* Wilcoxon's two-sample test.

Table 4 The relationship between IgA RF levels at onset and the subsequent requirement for gold, penicillamine, and steroids

\begin{tabular}{|c|c|c|c|c|}
\hline \multirow{2}{*}{$\begin{array}{l}\text { IgA RF level } \\
\text { (first visit) }\end{array}$} & \multirow{2}{*}{$\begin{array}{l}\text { No. of } \\
\text { patients }\end{array}$} & \multicolumn{2}{|c|}{ Treatment opportunities* } & \multirow[t]{2}{*}{ Significance } \\
\hline & & Used & Not used & \\
\hline $\begin{array}{l}\geqslant 10 \mathrm{U} / \mathrm{ml} \\
<10 \mathrm{U} / \mathrm{ml}\end{array}$ & $\begin{array}{r}7 \\
26\end{array}$ & $\begin{array}{l}14 \\
14\end{array}$ & $\begin{array}{r}7 \\
64\end{array}$ & $\begin{array}{l}\chi^{2}=17.0 \\
p<0.001\end{array}$ \\
\hline
\end{tabular}

* Each patient might have been treated with any or all of gold, penicillamine, or oral prednisolone.

$\chi^{2}$ test with Yates's correction. 
these three drugs for each patient, the number of treatment opportunities for $n$ patients was $3 n$. Thus defined, the seven patients who presented with raised IgA RF required significantly more drugs than the remaining $26(p<0) \cdot 001, \chi^{2}=17 \cdot 0, \chi^{2}$ test with Yates's correction), and this difference remained significant when the five non-RA patients were excluded $\left(p<0.001, \chi^{2}=12 \cdot 1\right)$.

\section{Discussion}

The disease activity in the prospective group at the conclusion of the study, expressed as RAI, GS, or IDA, correlated significantly with the number of erosions on the last available hand and wrist $x$-ray, and it is well established that the occurrence of erosions in RA strongly indicates poor prognosis. ${ }^{20}$ Consequently it seems valid to use the erosion count as objective evidence of outcome when assessing the prognostic value of RFs.

Our data indicate that an early rise in serum $\operatorname{IgA}$ RF during the course of RA is strongly predictive of a severe disease with early appearance of erosions (Fig. 2). Apart from a recent preliminary communication from our group ${ }^{21}$ the question of whether IgA RF may be associated with prognosis has been left largely unexplored. Although the number of patients in our study is small, the association of IgA RF with adverse outcome is strong, and the much greater requirements of the group with raised IgA RF for gold, penicillamine, and steroids suggest that serum IgA RF may be a valuable adjunct when deciding whether to start the individual patient on specific drugs.

Raised IgM RF levels in early RA were not associated with adverse outcome in our group. This may seem surprising in view of the known association of positive RF agglutination tests with adverse prognosis in RA. However, although the polyvalent IgM RF is known to be an efficient agglutinator, it has now been reported that $\operatorname{IgA}$ RF may largely be in the form of a J-chain containing polymer. ${ }^{22} 23$ Consequently, IgA RF might cause positive agglutination reactions, and the reports of Elkon et al. ${ }^{22}$ and Van Snick and Masson ${ }^{24}$ indeed showed this to be the case. Furthermore we found a significant correlation in the prospective group between levels of $\operatorname{IgM} \mathrm{RF}$ and $\operatorname{IgA} \mathrm{RF}(\mathrm{r}=0.676, \mathrm{n}=651$, $\mathrm{p}<0.001)^{12}$ which also may link IgA RF to positive agglutination tests.

$\operatorname{Ig} \mathrm{A}$ autoantibodies, including $\operatorname{IgA} \mathrm{RF}$, have received much less attention than IgG and IgM autoantibodies. $\operatorname{IgA}$ antibodies are generally poor at activating complement and phagocytic cells, and analysis of synovial fluid immune complexes in RA has not revealed much IgA. " The pathogenic potential of IgA RF may therefore be questioned although $\operatorname{IgA}$ autoantibody has been associated with haemolytic anaemia ${ }^{25}$ and RA with immune complex nephritis. ${ }^{26}$ Furthermore, the persistence of $\operatorname{IgA}$ anti-yersinia antibodies after infection with yersinia has been associated with the development of reactive arthritis. ${ }^{27}$ It is possible that the presence of IgA RF in severe RA reflects relatively active involvement of $\mathrm{T}$ cells in the pathogenic process because the generation of $\operatorname{IgA}$ antibodies is more dependent upon $\mathrm{T}$ cell help than is the production of IgM and possibly also IgG antibodies. ${ }^{2 x}$ This hypothesis would agree with the view of Janossy et al. ${ }^{29}$ that RA is characterised by an imbalance of $\mathrm{T}$ lymphocyte/macrophage immunoregulatory mechanisms with a relative dominance of $\mathrm{T}$ helper effects. IgA RF might therefore be a marker for heightened $\mathrm{T}$ helper activity in severe RA rather than pathogenic in itself.

We suggest that IgA RF may be a specific early marker for a poor prognosis in RA, perhaps justifying early treatment with specific drugs.

This work was supported by grants from the Icelandic Science Foundation. Astra-Syntex Scandinavia Ltd, and NATO. I.T. was in receipt of a British Council scholarship for 14 months during the course of this work.

\section{References}

1 Rasker J J. Cosh J A. Cause and age at death in a prospective study of 100 patients with rheumatoid arthritis. Ann Rheum Dis 1981: 40: 115-20.

2 Sigler J W. Bluhm G B. Duncan H. Sharp J T. Ensign D C. McCrum W R. Gold salts in the treatment of rhcumatoid arthritis. A double-blind study. Ann Intern Med 1974: 80: 21-6.

3 Luukkainen R. Isomäki H. Kajander A. Effect of gold treatment on the progression of crosions in RA patients. Scand J Rheumatol 1977: 6: 123-7.

4 Zvaifler N J. Gold and antimalarial therapy. In: McCarty D J. ed. Arthritis and allied conditions. 9th ed. Philadelphia: Lea and Febiger, 1979: 355-67.

5 Luukkainen R. Kajander A. Isomäki H. Effect of gold on progression of erosions in rheumatoid arthritis. Better results with carly treatment. Scand J Rheumatol 1977: 6: 189-92.

6 Duthic J J R. Brown P E. Truclove L H. Baragar F D. Lawric A J. Course and prognosis in rheumatoid arthritis. A further report. Ann Rheum Dis 1964: 23: 193-204.

7 Otten H A. Boerma F W. Significance of the Waaler-Rose test. streptococcal agglutination. and antistreptolysin titre in the prognosis of rheumatoid arthritis. Ann Rheum Dis 1959; 18: 24-8.

8 Jacoby R K. Jayson M I V. Cosh J A. Onset. carly stages and prognosis of rheumatoid arthritis: a clinical study of 100 patients with 11 year follow-up. $B r$ Med J 1973; ii: 96-100).

9 Fleming A. Crown J M. Corbett M. Early rheumatoid disease. I. Onset. Ann Rheum Dis 1976: 35: 357-60.

10 Greenbury C L. Moore D H. Nunn L A C. Reaction of 7 S and $19 S$ components of immune rabbit antisera with human group $A$ and $\mathrm{AB}$ red cells. Immunology 1963; 6: 421-33.

11 Male D. Roitt I M. Hay F C. Analysis of immune complexes in synovial effusions of patients with rheumatoid arthritis. Clin Exp Immunol 1989): 39: 297-306. 


\section{Teitsson, Withrington, Seifert, Valdimarsson}

12 Withrington R H, Teitsson I, Valdimarsson $\mathrm{H}$. Seifert $\mathrm{M} \mathrm{H}$. Prospective study of early rheumatoid arthritis. II. Association of rheumatoid factor isotypes with fluctuations in disease activity. Ann Rheum Dis Same issuc.

13 Teitsson I. Antiglobulins in relation to rheumatic diseases: development of ELISA assays and their application in prospective and family surveys. London: University of London. 1983. $\mathrm{PhD}$ thesis.

14 Teitsson I, Valdimarsson H. ELISA for $\operatorname{IgM}, \operatorname{IgA}$ and $\operatorname{IgG}$ rheumatoid factors (RF). Monoclonal antibodies and $F\left(a b^{\prime}\right)$, enzyme conjugates obviate the necd for inactivation of IgM RF in IgG and IgA RF assays. J Immunol Methods in press.

15 Wernick R, LoSpalluto J J, Fink C W, Ziff M. Serum IgG and IgM rheumatoid factors by solid phase radioimmunoassay. A comparison between adult and juvenile rheumatoid arthritis Arthritis Rheum 1981; 24: 1501-11.

16 Voller A, Bidwell D E, Bartlett A. Enzyme immunoassays in diagnostic medicine. Theory and practice. Bull WHO 1976; 53: 55-65.

17 Anderson S G, Bentzon M W, Houba V, Krag P. International reference preparation of rheumatoid arthritis serum. Bull WHO 1970; 42: 311-8.

18 Sharp J T, Lidsky M D, Collins L C, Moreland J. Methods of scoring the progression of radiologic changes in rheumatoid arthritis: correlation of radiologic, clinical and laboratory abnormalities. Arthritis Rheum 1971; 14: 706-20.

19 Finnic A, Mason M, Muir C. Evaluation of the RAHA test for rheumatoid factor. Med Lab Technol 1974; 31: 323-6.

20 Brook A. Fleming A, Corbett M. Relationship of radiological change to clinical outcome in rheumatoid arthritis. Ann Rheum Dis 1977; 36: 274-5.

21 Teitsson I, Withrington R H, Seifert $M H$, Valdimarsson $H$. Rheumatoid factors (RF) in early rheumatoid arthritis (RA): A prospective study. A combined meeting of BARR. the Heberden Society, RSM Section of R\&R and the Irish Society for R\&R. 22-23 September, 1983. University of Leeds, abstract no. 10.

22 Elkon K B. Delacroix D L. Gharavi A E, Vacrman J P. Hughes G R V. Immunoglobulin A and polymeric IgA rhcumatoid factors in systemic sicca syndrome: partial characterisation: $J$ Immunol 1982; 129: 576-81.

23 Koopman W J. Schrohenloher R E, Miller R K. Moldoveanu Z. Mestecky J. Characterisation of IgA rheumatoid factor (RF) in rheumatoid arthritis (RA) sera and synovial fluids (SF). Arthritis Rheum 1983; 26 (suppl): s17.

24 Van Snick J L. Masson P L. Incidence and specificitics of IgA and IgM anti-IgG autoantibodies in various mouse strains and colonies. J Exp Med 1980; 151: 45-55.

25 Wolf C F W, Wolf D J, Peterson P, Brandsletter R D, Hansen D E. Autoimmune hacmolytic anacmia with predominance of IgA autoantibody. Transfusion 1982; 22: 238-40.

26 Farhangi M, Luger A M. Morris A D. Pathogenic role of a monoclonal IgA (kappa) anti-IgG paraprotein associated with haemorrhagic diathesis, rheumatoid arthritis, vascular purpura and acute membranoproliferative glomerulonephritis. $J$ Clin Immunol 1982; 2: 75-85.

27 Granfors K, Viljanen M. Tiilikainen A. Toivanen A. Persistence of IgM IgG and IgA antibodies to yersinia in yersinia arthritis. J Infect Dis 1980; 141: 424-9.

28 Coutinho A, Benner R. Björklund M. et al. A 'trans' perspective on the control of immunoglobulin $\mathrm{C}$ gene expression Immunol Rev 1982; 67: 87-114.

29 Janossy G, Panayi G S. Duke O, Bofill M, Poulter L W. Goldstein G. Rheumatoid arthritis: a disease of T-lymphocyte/ macrophage immunoregulation. Lancet 1981; ii: 839-42. 